\title{
Adaptive Behavior in Children with Intellectual Disabilities
}

\author{
Hazir Elshani ${ }^{1}$ \\ Eglantina Dervishi ${ }^{2 *}$ \\ Silva Ibrahimi ${ }^{3}$ \\ Altin Nika 4 \\ Mimoza Maloku Kuqi5 \\ ${ }^{1}$ Office for Psychological Issues, \\ Municipal Directorate of Education, Drenas, Kosovo \\ ${ }^{2}$ Department of Psychology and Pedagogy, Faculty of Social Sciences, \\ University of Tirana, Bulevardi Gjergj Fishta, Tirana, Albania \\ ${ }^{3}$ Department of Psychology "Albanian University", Bulevardi Zogu I, 1001, Tirana, Albania \\ ${ }^{4}$ Center for Counseling and Psychological Services, Shkodra, Albania \\ ${ }^{5}$ Pediatric Clinic, University Clinical Center of Kosovo \\ ${ }^{*}$ Corresponding Author
}

DOI: https://doi.org/10.36941/mjss-2020-0o61

\section{Abstract}

Children with intellectual disabilities experience deficits in all the areas of adaptive function and some other aspects, unfortunately little is known about the independent functioning among gender and age related to these impairments in this type of neurogenetic disorders as intellectual disabilities. Adaptive behavior is essential for an optimal functioning in these categories. 53 participants aged between 5 and 11 in school years have been administered the Vineland Adaptive Behavior Scales, Montreal Cognitive Assessment scale (MoCA) and Raven's Standard Progressive Matrices (IQ). Motor abilities are the area that is more affected in children with intellectual disabilities with a significant impairment appeared at an early age, which remain low even in the following years. These differences are potentially oriented by the etiologies related to the disorder. Adaptive behavior is an important area of challenge for children with intellectual disabilities throughout their development. Daily living skills and competencies are also a significant strength in relation to other areas of adaptive functioning.

Keywords: Intellectual disability, children, adaptive behavior, daily living skills, motor skills

\section{Introduction}

The definition of mental retardation in the DSM-5 [American Psychiatric Association, 2013] recognizes that the intellectual deficit of individuals with intellectual disabilities affects both the intellectual area [ID] and the adaptive functions of the individual [Will, Caravella, Hahn, Fidler \& Roberts, 2018]. ID is manifested mainly by the lack of understanding, reasoning, problem solving, planning and abstract thinking [Woodman, Mailick, Anderson \& Esbensen, 2014]. Coping with the 
diagnosis of intellectual disability puts children and their family in front of a new reality filled with unpredictable challenges and difficulties [Hahn, Brady, Warren \& Fleming, 2015; Golya \& McIntyre, 2018]. The need that these children have to function in many areas requires the support and the follow-up of caregivers of children with intellectual disabilities [Tan, van Gorp, Voorman, Geytenbeek \& Reinders-Messelink et al., 2020; Price, Morris \& Costello, 2018; Warren, Brady, Fleming \& Hahn, 2017]. Challenging for the family and the child may be aspects related to dressing or preparing food, following rules and building and maintaining relationships with others[Picardi, Gigantesco, Tarolla, Stoppioni \& Cerbo et al., 2018; Mervis \& Pitts, 2015; Salomone, Shephard, Milosavljevic, Johnson, Charman \& BASIS Team, 2018; Wolfe, Stueber, McQuillin, Jichi \& Patch et al., 2018].

Often children with intellectual disabilities have obvious difficulties compared to their peers in terms of communication that relates to the ability to understand and react after receiving a message from another person who tries to interact with them [Fenning \& Baker, 2012]. Their ability to write and communicate messages in various forms also have visible difficulties [Farmer, Adedipe, Bal, Chlebowski \& Thurm, 2020; Hill, Gray, Kamps \& Enrique Varela, 2015]. Another area that encounters difficulties is the ability of the child with intellectual disabilities to independently perform all those activities related to meeting everyday life needs [Green \& Baker, 2011]. This implies that children with intellectual disabilities present obvious difficulties in aspects related to interpersonal relationships, play, leisure and coping skills [Mervis, Klein-Tasman, Huffmn,Vellerman \&Pitss et al.,2015]. These difficulties vary from one child to another influenced by the severity of the symptoms [Pugliese, Anthony, Strang, Dudley \& Wallace et al., 2016]. Thus, children diagnosed with severe intellectual disabilities have a much greater level of difficulty compared to children with moderate and mild intellectual disabilities [Han, Thurm, Golden Williams, Joseph \& Zein et al. 2013]. Referring to the mild intellectual ability, the level of difficulty allows the clinician to work better with the child and if there are favorable conditions related to external and internal support sources, the prognosis of the evolution of the disorder is predicted to be positive [ Mazon, Consel, Amestoy \& Hesling et al., 2019; Rice, Zablotsky, Avila, Colpe \& Schieve et al., 2016; Green, Caplan \& Baker, 2014; Reichow, Hume, Barton \& Boyd, 2018]. In addition to these areas that associate with intellectual disability, what is important for a good understanding of a child's needs is a careful assessment of maladaptive behaviors [Doody, Murphy, Lyons, Gallen \& Ryan et al., 2019] such as internalizing and externalizing behaviors [Rods, Chavira \& Baker, 2017]. An exploration of maladaptive behavior helps us identify the problematic aspects and manage the case, avoiding any risk that may impinge the child [Sullivan, Diepstra, Heng, Ally \& Bradley et al., 2018; Caravella \& Roberts, 2017].

\section{Method}

The aim of this study is to assess the main areas of adaptive behaviors present in children with intellectual disabilities.

Hypothesis 1 : There is a strong and positive relationship between the level of mental retardation and the level of delay in social maturity.

Hypothesis 2: There is a strong and positive relationship between the level of cognitive impairment and the level of retardation in social maturity.

Hypothesis 3: There are no statistically and significant differences in the level of delay in social maturity related to the gender, place of residence, age and school grade of children.

\subsection{Sample}

A sample of 53 children diagnosed with intellectual disabilities was referred for evaluation to the office for Psychological Issues in the Administration of the Regional Directorate of Education in Drenas, Kosovo. 


\subsection{Instruments}

Instruments used to conduct this study were:

The Vineland test (The adaptive behavior assessment) school version(Vineland / 3-18) conceived for children of preschool and school age from 3 to 18 years old. It consists of 5 areas as communication, skills in daily life, socialization, motor skills and maladaptive behaviors. The Vineland Social Maturity Scales (VSMS), measure social competence in individuals from all ages. The test represents a significant contribution in the assessment of adaptive behavior or behaviors that make a person independent and socially responsible.

MoCA (Montreal Cognitive Assessment) Test. This test assesses various cognitive areas such as: attention and concentration, executive functions, memory, conceptual thinking, visual-constructive skills, speech / language, calculations and orientation. The requested time to administer MOCA is approx. 10 minutes.

The Raven Progressive Color Matrix (IQ) test aims to measure IQ. This test is designed to measure psychomotor development in children aged 5 to 11 years old who show difficulties in cognitive and motor functions. This test is used to measure fluid intelligence and crystallized intelligence. It is called progressive because it starts with mild statements and comes up raising difficulty, while colored because Raven used the color test to be more appealing to children. This test belongs to nonverbal tests.

\subsection{Ethics}

Data for the current study were collected in the period from June 2019 to February 2020. In the first step for the identification of children,the authors obtained a permission and approval from the Ethics Commission at the Municipal Directorate of Education, the Municipality of Drenas. Written permission was also obtained from each parent of the children to conduct the study. Parents were made familiar with the purposes of the study, with the instruments that would be used with their children and with how the study results would be treated and published, ensuring complete anonymity and confidentiality to both parents and children.

\section{Results}

Data for this study were collected from 53 children from the Municipality of Drenas in Kosovo. These children are enrolled in various levels of compulsory education in Kosovo. The study involved 24 female and 29 male children. Expressed in percentage, the participation of male children in this study was $54.7 \%$ of all children, while the participation of female children was equal to $45.3 \%$. In the preparatory class were 8 children or $15.1 \%$ of all children participating in the study. In the first grade there were 6 children or $11.3 \%$ of all children. In the second grade there were 7 children or $13.2 \%$ of all children. In the third grade were 6 children or $11.3 \%$. In the fourth grade there were 9 children or $17 \%$. In the fifth grade there were 8 children or $15.1 \%$. In the sixth grade there were 9 children or $17 \%$. Most of these children $(7$ children or $63.6 \%$ ) were boys and the rest (4 children or $36.45 \%$ ), girls. These children were identified in almost all grades, starting from the preparatory grade to the sixth grade, with the exception of the first grade. Most of these children (54.5\%) result in moderate mental retardation. Another part (36.4\%) had mild mental retardation and only 1 child resulted in severe mental retardation.

Table 1. Average age of children, according to gender

\begin{tabular}{|l|l|c|c|c|c|c|}
\hline \multicolumn{2}{|l|}{ Children age } & $\mathrm{N}$ & Minimum & Maximum & Mean & Std. Deviation \\
\hline \multirow{2}{*}{ Female } & Children age in years & 24 & 5.03 & 11.85 & 8.8388 & 2.19320 \\
\cline { 2 - 7 } & Valid N (listwise) & 24 & & & & \\
\hline \multirow{2}{*}{ Male } & Children age in years & 29 & 5.09 & 11.79 & 8.6921 & 2.16806 \\
\cline { 2 - 7 } & Valid N (listëise) & 29 & & & & \\
\hline
\end{tabular}


The average age of the girls participating in the study was similar to that of the boys. Specifically, the minimum age of girls was 5.03 years old, while the maximum age was 11.85 years and the average age of girls was 8.8 years old $(\mathrm{SD}=\mathbf{2 . 1 9}$ ). The minimum age of boys was 5.09 years, while the maximum age was 11.79 years and the average age of boys was 8.69 years old $(\mathrm{SD}=\mathbf{2 . 1 6})$.

From the current study it resulted that the majority of the children tested (77.4\%) are at the rate of the level of adaptive abilities (social maturity) according to their respective age. Only $20.8 \%$ of children are one year later in adaptive behaviors and only 1 child is 2 years or more later in adaptive behaviors.

Once the general picture of adaptive behaviors of these children diagnosed with intellectual disabilities has been clarified, the possible differences of this variable according to the gender, place of residence, class and age of the children will be analyzed.

Most girls (83.3\% of them) and most boys ( $72.4 \%$ of them) have appropriate behaviors developed according to their age. There are $16.7 \%$ of girls and $24.1 \%$ of boys who have a delay of 1 year in adaptive behaviors. It is noted that, there is an almost equal distribution among children who are at the rate of behaviors appropriated to their age development. $48.8 \%$ of them are girls and $51.2 \%$ are boys. Meanwhile, the situation is slightly different in children who have a year of delay in their adaptive behaviors. Most of them are boys, respectively $63.6 \%$ and the rest $36.4 \%$ are girls. The analysis goes further through the conduct of a non-parametric test (chi square test).

Table 2. Chi-Square Test between gender and social maturity

\begin{tabular}{|l|c|c|c|}
\hline & Values & df & Asy. Sign. (2-sided) \\
\hline Pearson Chi-Square & $1.383^{\mathrm{a}}$ & 2 & .501 \\
\hline Likelihood Ratio & 1.767 & 2 & .413 \\
\hline Linear-by-Linear Association & 1.193 & 1 & .275 \\
\hline N of Valid Cases & 53 & & \\
\hline $\begin{array}{l}\text { a. 3 cells (50.0\%) have expected count less than } 5 . \\
\text { The minimum expected count is .45. }\end{array}$ \\
\hline
\end{tabular}

The results of the Chi square test show that there is no statistically significant relationship between gender and adaptive behaviors of children $(p=0.501>0.05)$. Thus, the differences observed in the descriptive analyzes are not confirmed by the non-parametric test.

Even the non-parametric Mann-Whitney test confirms the same finding. There are no statistically significant differences in the level of child-adaptive behaviors related to the child gender. In this case, the adaptive behavior variable is considered an ordinary variable. The analysis shows that this variable (level of social maturity) does not have a normal distribution of data. The MannWhiteny test showed that there is no statistically significant difference between levels of social maturity and gender of children $(\mathrm{p}=0.325>0.05)$. About $75 \%$ of children in preparatory classes are in the normal rate of adaptive behaviors while $35 \%$ of them are a year late in adaptive behaviors. All first graders are at the normal rate of adaptive behaviors, according to their age development. $85.7 \%$ of children in the second grade have on the normal rate and $14.3 \%$ had a year delay in adaptive behaviors. $66.7 \%$ of third grade children are at the rate while $33.3 \%$ of them are one year later in adaptive behaviors. $88.9 \%$ of fourth graders are in the rate and $12.5 \%$ are one year later in adaptive behaviors. $44.4 \%$ of sixth graders are in the normal rate and the same figures $(44.45 \%)$ are for those with one year of delay of adaptive behaviors. Since the adaptive behavior variable has an abnormal data distribution, to analyze the relationship between this variable and the other classroom variable, the Spearman coefficient was calculated. It results that there is no statistically significant relationship between the class of students and the level of adaptive behaviors of children $(p=0.118>0.05)$. This means that there are no changes in the level of adaptive behaviors of children, according to the classes they attend. It also resulted that, there is no statistically significant relationship between the biological age of students and the levels of adaptive behaviors $(p=0.260>0.05)$. This means that the 
levels of adaptive behaviors do not change depending on the biological age of the children. At the normal rate of adaptive behaviors are most of the children living in rural areas and also most of the children living in urban areas. Specifically, $76.7 \%$ of children living in rural areas and $78.3 \%$ of children living in urban areas are at the normal rate of adaptive behaviors. About $20 \%$ of children living in rural areas and $21.7 \%$ of children living in urban areas have a 1 year of delay in the manifestation of adaptive behaviors. It is observed that there is an almost equal distribution in urban and rural areas of children who are in the normal rate of adaptive behaviors. Specifically, in the rate of adaptive behaviors are about $56 \%$ of children living in rural areas and about $44 \%$ of children living in urban areas. The same situation is evident with children who show 1 year delay in adaptive behaviors.

Table 3. Relationship between the level of mental retardation,cognitive skills and adaptive behaviors

\begin{tabular}{|c|c|c|c|c|c|}
\hline & & & $\begin{array}{l}\text { IQ Col Progr } \\
\text { Matrix Test J } \\
\text { C Raven }\end{array}$ & $\begin{array}{c}\text { Cognitive skills for all } \\
\text { development areas } \\
\text { assessed by MoCA } \\
\text { Test }\end{array}$ & $\begin{array}{c}\text { Level of social } \\
\text { maturity } \\
\text { according to } \\
\text { Vineland scale }\end{array}$ \\
\hline \multirow{9}{*}{$\begin{array}{l}\text { Spearman's } \\
\text { rho }\end{array}$} & \multirow{3}{*}{$\begin{array}{l}\text { IQ Col Progr Matrix } \\
\text { Test J C Raven }\end{array}$} & Correlation Coefficient & 1.000 & $.599^{* *}$ & $.785^{* *}$ \\
\hline & & Sig. (2-tailed) &. & .000 & .000 \\
\hline & & $\mathrm{N}$ & 53 & 39 & 53 \\
\hline & \multirow{3}{*}{$\begin{array}{l}\text { Cognitive skills for all } \\
\text { development areas } \\
\text { assessed by MoCA Test }\end{array}$} & Correlation Coefficient & $.599^{* *}$ & 1.000 & $.770^{* *}$ \\
\hline & & Sig. (2-tailed) & .000 & . & .000 \\
\hline & & $\mathrm{N}$ & 39 & 39 & 39 \\
\hline & \multirow{3}{*}{$\begin{array}{l}\text { Level of social maturity } \\
\text { according to Vineland } \\
\text { scale }\end{array}$} & Correlation Coefficient & $.785^{* *}$ & $.770^{* *}$ & 1.000 \\
\hline & & Sig. (2-tailed) & .000 & .000 & . \\
\hline & & $\mathrm{N}$ & 53 & 39 & 53 \\
\hline
\end{tabular}

A statistically significant relationship between the level of mental retardation and the level of cognitive impairment $(\mathrm{p}=0.000<0.05, \mathrm{r}=0.599)$. The relationship between the level of mental retardation and the level of cognitive impairment is positive and moderate. This means that the more severe the level of mental retardation the more impaired the child's cognitive abilities are and vice versa. There is a statistically significant relationship between the level of mental retardation and the level of delay in adaptive behaviors $(\mathrm{p}=0.000<0.05, \mathrm{r}=0.785)$. The relationship between the level of mental retardation and the level of delay in adaptive behaviors is positive and strong. This means that the more severe the level of mental retardation the higher the delay in the child's adaptive behaviors and vice versa. There is a statistically significant relationship between the level of cognitive impairment and the level of delay in adaptive behaviors $(\mathrm{p}=0.00<0.05, \mathrm{r}=0.770)$. The relationship between the level of cognitive impairment and the level of delay in adaptive behaviors is positive and strong. This means that the more impaired the cognitive skills, the higher the delay in adaptive behaviors and vice versa.

\section{Discussions}

Adaptive behaviors are a priority for the overall functioning of the individual both in daily life activities as well as with favorable outcomes in all areas of cognitive functions, academic and general well-being of the child and his family [Scheffers, van Vugt \& Moonen, 2020 ; Bertollo \& Yerys, 2019; Pugliese, Anthony, Strang, Dudley \& Wallace et al., 2015; Bernard Paulais, Mazetto, Thiébaut, Nassif \& Costa Coelho De Souza et al., 2019]. Impairments in adaptive behavior are typical of children with intellectual disabilities and can usually be associated with many other neurodevelopmental disorders that are in comorbidity with AKI.

Based on the overall results of the study, it resulted that only one child had a severe level of 
intellectual disability. The rest of the children participating in the study mainly belonged to a moderate and mild level of intellectual disability. Referring to studies, moderate or severe levels of intellectual disability tend to severely impair a child's functioning in terms of socialization, communication, motor skills and daily motor skills [Hassiotis, Strydom, Crawford, Hall \& Omar et al., 2014; Hamburg, Lowe, Startin, Padilla \& Coppus et al., 2019]. It also resulted that difficulties in adaptive behaviors affect the increase of the child's problems in the field of cognitive functioning, developing obvious difficulties in their academic progress in every direction. What resulted from our study is that moderate, severe, and profound levels of intellectual disability tend to be associated with marked delays in adaptive behaviors.

This means that children with moderate or severe intellectual disabilities will show increased problems in terms of communication, ability to perform daily tasks, motor skills, socialization and an increasing tendency to exhibiting maladaptive behavior [Novell, Esteba-Castillo \& Rodriguez, 2020]. Another aspect that associates intellectual disability and adaptive behaviors related to the overall functioning of the child are cognitive abilities. It was found that in children diagnosed with moderate and severe intellectual disabilities, severe and profound problems with adaptive behaviors tended to increase with increasing the gravity of the symptoms and also to increase impairments in cognitive abilities in these children.

\section{Conclusions}

The current study suggests that the majority of children who participated in the study and who were diagnosed with intellectual disabilities, $77 \%$ of them, are in the normal rate of age-adaptive behaviors. It was noted that there are no statistically significant differences in the level of adaptive behaviors related to gender, age, grade and place of residence. Our findings showed that there is a strong and positive relationship between the level of mental retardation and the level of delay in adaptive behaviors. There is a strong and positive relationship between cognitive impairment and the level of delay in adaptive behaviors. The results suggest that school-age children with intellectual disabilities are in need of early intervention in all areas of adaptive behaviors with specific differences according to the severity level of intellectual disability.

\section{References}

Bernard Paulais, M. A., Mazetto, C., Thiébaut, E., Nassif, M. C., Costa Coelho De Souza, M. T., Stefani, A. P., Blanc, R., Gattegno, M. P., Aïad, F., Sam, N., Belal, L., Fekih, L., Kaye, K., Contejean, Y., Wendland, J., Barthélémy, C., Bonnet-Brilhault, F., \& Adrien, J. L. (2019). Heterogeneities in Cognitive and Socio-Emotional Development in Children With Autism Spectrum Disorder and Severe Intellectual Disability as a Comorbidity. Frontiers in psychiatry, 10, 508. https://doi.org/10.3389/fpsyt.2019.00508

Bertollo, J. R., \& Yerys, B. E. (2019). More Than IQ: Executive Function Explains Adaptive Behavior Above and Beyond Nonverbal IQ in Youth With Autism and Lower IQ. American journal on intellectual and developmental disabilities, 124(3), 191-205. https://doi.org/10.1352/1944-7558-124.3.191

Caravella, K. E., \& Roberts, J. E. (2017). Adaptive Skill Trajectories in Infants with Fragile X Syndrome Contrasted to Typical Controls and Infants at High Risk for Autism. Research in autism spectrum disorders, 40, 1-12. https://doi.org/10.1016/j.rasd.2017.05.002

Doody, O., Murphy, F., Lyons, R., Gallen, A., Ryan, J., Downey, J., \& Sezgin, D. (2019). Development of nursing quality care process metrics and indicators for intellectual disability services: a literature review and modified Delphi consensus study. BMC health services research, 19(1), 909. https://doi.org/10.1186/s12913019-4749-y

Farmer, C., Adedipe, D., Bal, V. H., Chlebowski, C., \& Thurm, A. (2020). Concordance of the Vineland Adaptive Behavior Scales, second and third editions. Journal of intellectual disability research : JIDR, 64(1), 18-26. https://doi.org/10.1111/jir.12691

Fenning, R. M., \& Baker, J. K. (2012). Mother-child interaction and resilience in children with early developmental risk. Journal of family psychology : JFP : journal of the Division of Family Psychology of the American Psychological Association (Division 43), 26(3), 411-420. https://doi.org/10.1037/aoo28287 
Golya, N., \& McIntyre, L. L. (2018). Variability in adaptive behaviour in young children with autism spectrum disorder. Journal of intellectual \& developmental disability, 43(1), 102-111. https://doi.org/10.3109/13668250.2017.1287886

Green, S., \& Baker, B. (2011). Parents' emotion expression as a predictor of child's social competence: children with or without intellectual disability. Journal of intellectual disability research : JIDR, 55(3), 324-338. https://doi.org/10.1111/j.1365-2788.2010.01363.x

Green, S., Caplan, B., \& Baker, B. (2014). Maternal supportive and interfering control as predictors of adaptive and social development in children with and without developmental delays. Journal of intellectual disability research : JIDR, 58(8), 691-703. https://doi.org/10.1111/jir.12064

Hahn, L. J., Brady, N. C., Warren, S. F., \& Fleming, K. K. (2015). Do Children With Fragile X Syndrome Show Declines or Plateaus in Adaptive Behavior?. American journal on intellectual and developmental disabilities, 120(5), 412-432. https://doi.org/10.1352/1944-7558-120.5.412

Hamburg, S., Lowe, B., Startin, C. M., Padilla, C., Coppus, A., Silverman, W., Fortea, J., Zaman, S., Head, E., Handen, B. L., Lott, I., Song, W., \& Strydom, A. (2019). Assessing general cognitive and adaptive abilities in adults with Down syndrome: a systematic review. Journal of neurodevelopmental disorders, 11(1), 20. https://doi.org/10.1186/s11689-019-9279-8

Han, J. C., Thurm, A., Golden Williams, C., Joseph, L. A., Zein, W. M., Brooks, B. P., Butman, J. A., Brady, S. M., Fuhr, S. R., Hicks, M. D., Huey, A. E., Hanish, A. E., Danley, K. M., Raygada, M. J., Rennert, O. M., Martinowich, K., Sharp, S. J., Tsao, J. W., \& Swedo, S. E. (2013). Association of brain-derived neurotrophic factor (BDNF) haploinsufficiency with lower adaptive behaviour and reduced cognitive functioning in WAGR/11p13 deletion syndrome. Cortex; a journal devoted to the study of the nervous system and behavior, 49(10), 2700-2710. https://doi.org/10.1016/j.cortex.2013.02.009

Hassiotis, A., Strydom, A., Crawford, M., Hall, I., Omar, R., Vickerstaff, V., Hunter, R., Crabtree, J., Cooper, V., Biswas, A., Howie, W., \& King, M. (2014). Clinical and cost effectiveness of staff training in Positive Behaviour Support (PBS) for treating challenging behaviour in adults with intellectual disability: a cluster randomised controlled trial. BMC psychiatry, 14, 219. https://doi.org/10.1186/s12888-014-0219-6

Hill, T. L., Gray, S. A., Kamps, J. L., \& Enrique Varela, R. (2015). Age and Adaptive Functioning in Children and Adolescents with ASD: The Effects of Intellectual Functioning and ASD Symptom Severity. Journal of autism and developmental disorders, 45(12), 4074-4083. https://doi.org/10.1007/s10803-015-2522-6

Mazon, C., Fage, C., Consel, C., Amestoy, A., Hesling, I., Bouvard, M., Etchegoyhen, K., \& Sauzéon, H. (2019). Cognitive Mediators of School-Related Socio-Adaptive Behaviors in ASD and Intellectual Disability Pre- and Adolescents: A Pilot-Study in French Special Education Classrooms. Brain sciences, 9(12), 334. https://doi.org/10.339o/brainscig120334

Mervis, C. B., \& Pitts, C. H. (2015). Children with Williams syndrome: Developmental trajectories for intellectual abilities, vocabulary abilities, and adaptive behavior. American journal of medical genetics. Part $C$, Seminars in medical genetics, 169(2), 158-171. https://doi.org/10.1002/ajmg.c.31436

Mervis, C. B., Klein-Tasman, B. P., Huffman, M. J., Velleman, S. L., Pitts, C. H., Henderson, D. R., WoodruffBorden, J., Morris, C. A., \& Osborne, L. R. (2015). Children with 7q11.23 duplication syndrome: psychological characteristics. American journal of medical genetics. Part A, 167(7), 1436-1450. https://doi.org/10.1002/ajmg.a.37071

Novell, R., Esteba-Castillo, S., \& Rodriguez, E. (2020). Efficacy and safety of a GABAergic drug (Gamalate ${ }^{\bowtie}$ B6): effects on behavior and cognition in young adults with borderline-to-mild intellectual developmental disabilities and ADHD. Drugs in context, 9, 212601. https://doi.org/10.7573/dic.212601

Picardi, A., Gigantesco, A., Tarolla, E., Stoppioni, V., Cerbo, R., Cremonte, M., Alessandri, G., Lega, I., \& Nardocci, F. (2018). Parental Burden and its Correlates in Families of Children with Autism Spectrum Disorder: A Multicentre Study with Two Comparison Groups. Clinical practice and epidemiology in mental health : CP E $E M H, 14,143-176$. https://doi.org/10.2174/1745017901814010143

Price, J. A., Morris, Z. A., \& Costello, S. (2018). The Application of Adaptive Behaviour Models: A Systematic Review. Behavioral sciences (Basel, Switzerland), 8(1), 11. https://doi.org/10.339o/bs8010011

Pugliese, C. E., Anthony, L. G., Strang, J. F., Dudley, K., Wallace, G. L., Naiman, D. Q., \& Kenworthy, L. (2016). Longitudinal Examination of Adaptive Behavior in Autism Spectrum Disorders: Influence of Executive Function. Journal of autism and developmental disorders, 46(2), 467-477. https://doi.org/10.1007/s10803-0152584-5

Pugliese, C. E., Anthony, L., Strang, J. F., Dudley, K., Wallace, G. L., \& Kenworthy, L. (2015). Increasing adaptive behavior skill deficits from childhood to adolescence in autism spectrum disorder: role of executive function. Journal of autism and developmental disorders, 45(6), 1579-1587. https://doi.org/10.1007/s10803-0142309-1 
Reichow, B., Hume, K., Barton, E. E., \& Boyd, B. A. (2018). Early intensive behavioral intervention (EIBI) for young children with autism spectrum disorders (ASD). The Cochrane database of systematic reviews, 5(5), CDoog26o. https://doi.org/10.1002/14651858.CDoo926o.pub3

Rice, C. E., Zablotsky, B., Avila, R. M., Colpe, L. J., Schieve, L. A., Pringle, B., \& Blumberg, S. J. (2016). Reported Wandering Behavior among Children with Autism Spectrum Disorder and/or Intellectual Disability. The Journal of pediatrics, 174, 232-239.e2. https://doi.org/10.1016/j.jpeds.2016.03.047

Rodas, N. V., Chavira, D. A., \& Baker, B. L. (2017). Emotion socialization and internalizing behavior problems in diverse youth: A bidirectional relationship across childhood. Research in developmental disabilities, 62, 1525. https://doi.org/10.1016/j.ridd.2017.01.010

Salomone, E., Shephard, E., Milosavljevic, B., Johnson, M. H., Charman, T., \& BASIS Team (2018). Adaptive Behaviour and Cognitive Skills: Stability and Change from 7 Months to 7 Years in Siblings at High Familial Risk of Autism Spectrum Disorder. Journal of autism and developmental disorders, 48(9), 2901-2911. https://doi.org/10.1007/s10803-018-3554-5

Scheffers, F., van Vugt, E., \& Moonen, X. (2020). Resilience in the face of adversity in adults with an intellectual disability: A literature review. Journal of applied research in intellectual disabilities : JARID, 33(5), 828-838. https://doi.org/10.1111/jar.12720

Sullivan, W. F., Diepstra, H., Heng, J., Ally, S., Bradley, E., Casson, I., Hennen, B., Kelly, M., Korossy, M., McNeil, K., Abells, D., Amaria, K., Boyd, K., Gemmill, M., Grier, E., Kennie-Kaulbach, N., Ketchell, M., Ladouceur, J., Lepp, A., Lunsky, Y., ... Witherbee, S. (2018). Primary care of adults with intellectual and developmental disabilities: 2018 Canadian consensus guidelines. Canadian family physician Medecin de famille canadien, 64(4), 254-279.

Tan, S. S., van Gorp, M., Voorman, J. M., Geytenbeek, J. J., Reinders-Messelink, H. A., Ketelaar, M., Dallmeijer, A. J., Roebroeck, M. E., \& Perrin-Decade study group (2020). Development curves of communication and social interaction in individuals with cerebral palsy. Developmental medicine and child neurology, 62(1), 132-139. https://doi.org/10.1111/dmcn.14351

Warren, S. F., Brady, N., Fleming, K. K., \& Hahn, L. J. (2017). The Longitudinal Effects of Parenting on Adaptive Behavior in Children with Fragile X Syndrome. Journal of autism and developmental disorders, 47(3), 768784. https://doi.org/10.1007/s10803-016-2999-7

Wolfe, K., Stueber, K., McQuillin, A., Jichi, F., Patch, C., Flinter, F., Strydom, A., \& Bass, N. (2018). Genetic testing in intellectual disability psychiatry: Opinions and practices of UK child and intellectual disability psychiatrists. Journal of applied research in intellectual disabilities : JARID, 31(2), 273-284. https://doi.org/10.1111/jar.12391

Woodman, A. C., Mailick, M. R., Anderson, K. A., \& Esbensen, A. J. (2014). Residential transitions among adults with intellectual disability across 20 years. American journal on intellectual and developmental disabilities, 119(6), 496-515. https://doi.org/10.1352/1944-7558-119.6.496

Will, E. A., Caravella, K. E., Hahn, L. J., Fidler, D. J., \& Roberts, J. E. (2018). Adaptive behavior in infants and toddlers with Down syndrome and fragile X syndrome. American journal of medical genetics. Part B, Neuropsychiatric genetics : the official publication of the International Society of Psychiatric Genetics, 177(3), 358-368. https://doi.org/10.1002/ajmg.b.32619 